\title{
The effect on respiratory mechanics when using a Jackson surgical table in the prone position during spinal surgery
}

\author{
Yoontae Nam, Ann Misun Yoon, Yoon Hee Kim, and Seok Hwa Yoon \\ Department of Anesthesiology and Pain Medicine, Chungnam National Univeristy School of Medicine, Daejeon, Korea
}

Background: Respiratory dynamics may be monitored and evaluated indirectly by measuring the peak inspiratory pressure and plateau pressure. In this study, the respiratory dynamics of patients undergoing spinal surgery using a Jackson surgical table were observed with a device after converting their position from supine to prone. The effects of the dynamic compliance and airway resistance were observed from the changes in peak inspiratory pressure and plateau.

Methods: Twenty five patients were selected as subjects scheduled to undergo lumbar spine surgery. After intubation, the patients were ventilated mechanically with a tidal volume of $10 \mathrm{ml} / \mathrm{kg}$ and a respiration rate of 10/min. Anesthesia was maintained with sevoflurane $1.5 \%$, nitrous oxide $2 \mathrm{~L} / \mathrm{min}$ and oxygen $2 \mathrm{~L} / \mathrm{min}$. The peak inspiratory pressure, plateau pressure, resistance, compliance, arterial oxygen tension, carbon dioxide tension, heart rate and arterial blood pressure were measured at 10 minutes after the induction of anesthesia. These parameters were measured again 10 minutes after placing the patient in the prone position.

Results: The prone position did not significantly affect the arterial oxygen tension, carbon dioxide tension, blood pressure and heart rate, but significantly increased the peak inspiratory pressure and resistance and decreased the dynamic compliance.

Conclusions: The peak inspiratory pressure was increased using a Jackson surgical table to minimize the abdominal pressure when converting from the supine to prone position. This might be due to a decrease in lung and chest compliance as well as an increase in airway resistance. (Korean J Anesthesiol 2010; 59: 323-328)

Key Words: Airway resistance, Dynamic compliance, Jackson surgical table, Peak inspiratory pressure, Prone position, Respiratory mechanics.

Received: April 23, 2010. Revised: 1st, May 26, 2010; 2nd, June 18, 2010. Accepted: June 25, 2010.

Corresponding author: Seok Hwa Yoon, M.D., Ph.D. Department of Anesthesiology and Pain Medicine, Chungnam National Univeristy School of Medicine, 55, Munhwa-ro, Jung-gu, Daejeon 301-747, Korea. Tel: 82-42-280-7840, Fax: 82-42-280-7962, E-mail: seohwy@cnu.ac.kr (c) This is an open-access article distributed under the terms of the Creative Commons Attribution Non-Commercial License (http:// creativecommons.org/licenses/by-nc/3.0/), which permits unrestricted non-commercial use, distribution, and reproduction in any medium, provided the original work is properly cited. 


\section{Introduction}

With the recent developments in surgical maneuvers and the increase in demand for noninvasive treatments, there have been an growing number of procedures that involve changes in body positioning and laparatomy. Patients under general anesthesia who undergo the above may experience biological changes due to the effects of these positional changes on the cardiovascular and respiratory system. Therefore, patients who undergo changes in body positioning require monitoring of the cardiovascular and respiratory systems. In controlled ventilation using modern anesthetic monitoring devices, the peak inspiratory pressure (PIP) and plateau pressure $\left(\mathrm{P}_{\text {plat }}\right)$ can be measured by a monitor, and the respiratory dynamics can be monitored and evaluated indirectly. When the amount of gas that expands the lungs is constant, the increase in PIP is considered to be the state when the airway resistance $\left(R_{a w}\right)$ increases, when pulmonary compliance decreases, or when both occur simultaneously [1].

In general anesthesia using muscle relaxants, moving the patient from the supine to prone position while using a mechanical ventilator for controlled ventilation affects the patient's respiratory dynamics and vital signs. Owing to the pressure on the abdomen, the internal organs push the diaphragm towards the direction of the head. In addition, the weight of the trunk decreases the diameter of the chest. With such movement limitations, the respiratory compliance decreases by $20-30 \%$ and the PIP increases. Therefore, the increase in PIP in the prone position has been attributed to the decrease in respiratory compliance [2-4].

On the other hand, some studies employed surgical tables with abdomen rolls to allow for the free movement of the abdomen. Therefore, the prone position rather than the supine position has been reported to improve the respiratory dynamic changes. Pelosi et al. [5] reported that the prone position during general anesthesia improves the lung volume and oxygenation without significantly altering the respiratory, pulmonary, or chest wall compliance. In addition, Palmon et al. [6] stated that the prone position using a Jackson surgical table does not significantly change the PIP or pulmonary compliance in patients with a normal weight. The use of a Jackson surgical table rather than a Wilson surgical table or a chest roll causes the least change in PIP and pulmonary compliance in patients with both normal and abnormal weights.

In this study, the increase in PIP was monitored using a patient monitoring device when changes in body positioning to the prone position were made using a Jackson surgical table. The authors also made the assumption that the change in PIP affects the pulmonary compliance and $\mathrm{R}_{\mathrm{aw}}$. Patients scheduled to undergo spinal surgery using a Jackson surgical table were moved from the supine to the prone position to observe the effects of the PIP and $\mathrm{P}_{\text {plat }}$ on the dynamic compliance $\left(\mathrm{C}_{\mathrm{dyn}}\right)$ and $\mathrm{R}_{\mathrm{aw}}$ using a respiratory dynamics monitoring device.

\section{Materials and Methods}

After gaining the approval of the ethics committee, the study was performed on 25 American Society of Anesthesiologists' physical status class I \& II male and female adult patients, aged 20-65 years, who were scheduled to undergo surgery under general anesthesia for lumbar disc herniation or spinal stenosis. They agreed to participate after having being explained the study and after they had asked questions. Patients were excluded if they had a history of abnormalities in the cardiovascular system or respiratory system, or if they had spinal disorders that had caused changes to the respiratory system, such as scoliosis, lordosis, kyphosis and ankylosing spondylitis. There were 25 patients with a mean age and body mass index of $44.1 \pm 13.2$ years and $24.8 \pm 3.1 \mathrm{~kg} / \mathrm{m}^{2}$, respectively (Table 1 ).

All patients were fasted from midnight before surgery. On the day of surgery, midazolam $2 \mathrm{mg}$ and glycopyrrolate $0.2 \mathrm{mg}$ were administered IM, and famotidine $20 \mathrm{mg}$ was administered IV 30 minutes before arriving into the OR. On the operating table a patient monitoring device (24c Omnicare ${ }^{\circledR}$, Hewlett Packard, Houston, TX, USA) was used for continuous monitoring of the electrocardiography, heart rate and oxygen saturation. In all patients, proper mask ventilation was confirmed if the patient lost consciousness after the IV administration of propofol when anesthesia was induced. Rocuronium 0.8 $\mathrm{mg} / \mathrm{kg}$ was administered IV for adequate muscle relaxation. Muscle relaxation was confirmed 2 minutes after administering rocuronium IV. Intubation was then performed using a wirereinforced tube, $8.0 \mathrm{~mm}$ in diameter for males and $7.5 \mathrm{~mm}$ in diameter for females. After confirming by auscultation that the breath sounds of both lungs were the same, the intubation tube was fixed at the depth of $23-24 \mathrm{~cm}$ for males and $21-22$ $\mathrm{cm}$ for females. Before starting the procedure, anesthesia was maintained by $\mathrm{O}_{2} 2 \mathrm{~L} / \mathrm{min}, \mathrm{N}_{2} \mathrm{O} 2 \mathrm{~L} / \mathrm{min}$, and sevoflurane 1.5 vol\%. Mechanical ventilation was set at a constant pace of a tidal volume $10 \mathrm{ml} / \mathrm{kg}$ and a respiration rate of $10 \mathrm{bpm}$. In the radial artery, a 20 gauge arterial catheter was placed to allow

Table 1. Demographic Data

\begin{tabular}{lc}
\hline No. of patient & 25 \\
Age $(\mathrm{yr})$ & $44.1 \pm 13.2$ \\
Height $(\mathrm{cm})$ & $164.0 \pm 10.4$ \\
Weight $(\mathrm{kg})$ & $67.2 \pm 1.3$ \\
BMI $\left(\mathrm{kg} / \mathrm{m}^{2}\right)$ & $24.8 \pm 3.1$ \\
Tidal volume $(\mathrm{ml})$ & $565.4 \pm 123.9$ \\
Gender $(\mathrm{M} / \mathrm{F})$ & $14 / 11$ \\
\hline
\end{tabular}

Values are means \pm SD or number of patients. BMI: body mass index. 
continuous measurements of the arterial blood pressure and for arterial blood sampling. After the required 10 minutes after endotracheal intubation to allow the vital signs to stabilize and for the changes in pulmonary compliance and pulmonary resistance to return to the state before airway irritation [7], a respiratory dynamics monitoring device (Ventcheck ${ }^{\circledR}$, Novametrix Medical System, Wallingford, CT, USA) was connected to the end of the endotracheal tube to measure the PIP, $P_{\text {plat }}, R_{a w}$, and $C_{d y n}$. All values were measured 3 times, and the median value was used for further analysis. The arterial $\mathrm{PaO}_{2}$ and $\mathrm{PaCO}_{2}$ were measured by arterial analysis, and the blood pressure and heart rate were monitored. All patients used a Jackson surgical table for the prone position. This was done using the method proposed by Smith [8], which involved supporting the upper chest and abdomen by a roll and allowing for free movement of the abdomen. The head was kept in the neutral position by placing it on a horse-shoe shaped head rest. After confirming that the fixed position of the tubes of the patient in the prone position did not change, the breath sounds of both lungs were confirmed by auscultation to be the same. After the patient was stabilized for 10 minutes, the respiratory dynamics were measured using the same methods as in the

Table 2. Change in Arterial Gas Tension and Vital Signs in the Supine and Prone Positions

\begin{tabular}{lcc}
\hline & Supine & Prone \\
\hline $\mathrm{PaO}_{2}$ at $\mathrm{FiO}_{2} 0.5(\mathrm{mmHg})$ & $251.7 \pm 15.1$ & $283.6 \pm 10.7$ \\
$\mathrm{PaCO}_{2}(\mathrm{mmHg})$ & $37.1 \pm 1.0$ & $35.5 \pm 1.0$ \\
$\mathrm{HR}(\mathrm{beat} / \mathrm{min})$ & $74.7 \pm 2.7$ & $73.4 \pm 2.4$ \\
$\mathrm{SAP}(\mathrm{mmHg})$ & $102.9 \pm 2.5$ & $103.4 \pm 2.8$ \\
$\mathrm{DAP}(\mathrm{mmHg})$ & $58.4 \pm 2.5$ & $62.7 \pm 2.2$
\end{tabular}

The values are mean $\pm \mathrm{SD}$. $\mathrm{PaO}_{2}$ : arterial oxygen tension, $\mathrm{PaCO}_{2}$ : arterial carbon dioxide tension, HR: heart rate, SAP: systolic arterial pressure, DAP: diastolic arterial pressure.

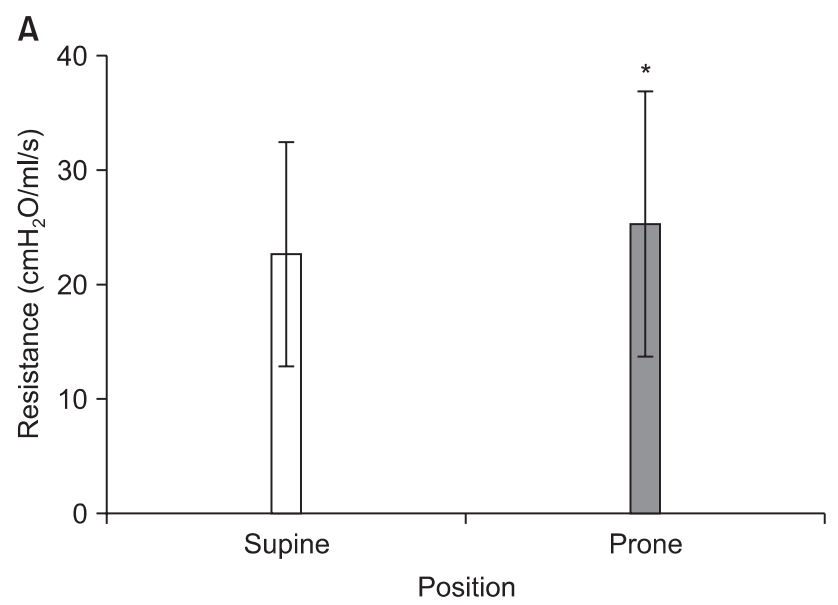

supine position and compared. All measurements are reported as the mean \pm SD. Data analysis was performed by SPSS (version 12.0, SPSS inc., Chicago, IL, USA) using a paired t-test. A P value $<0.05$ was considered significant.

\section{Results}

When changing the body positioning of the patient from the supine position to the prone position, the mean arterial $\mathrm{PaO}_{2}$ increased from $251.7 \pm 15.1 \mathrm{mmHg}$ to $283.6 \pm 10.7 \mathrm{mmHg}$. The mean $\mathrm{PaCO}_{2}$ decreased from $37.1 \pm 1.0 \mathrm{mmHg}$ to $35.5 \pm 1.0$ $\mathrm{mmHg}$. However, the differences in both parameters were not statistically significant. There were no significant changes in the systolic and diastolic blood pressure or the heart rate (Table 2).

The PIP significantly increased $(15.3 \pm 2.8 \mathrm{mmHg}$ vs. $16.7 \pm 2.7$ $\mathrm{mmHg}, \mathrm{P}<0.05)$ but there were no significant changes in the

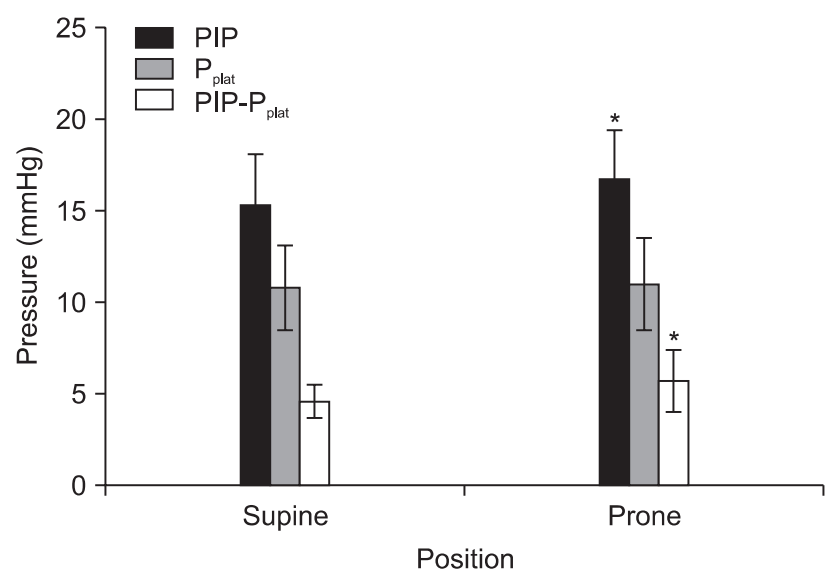

Fig. 1. Change in peak inspiratory pressure (PIP), plateau airway pressure $\left(\mathrm{P}_{\text {plat }}\right)$ and PIP - $\mathrm{P}_{\text {plat }}$ when moving from the supine to prone position. $* \mathrm{P}<0.05$ versus the supine position.

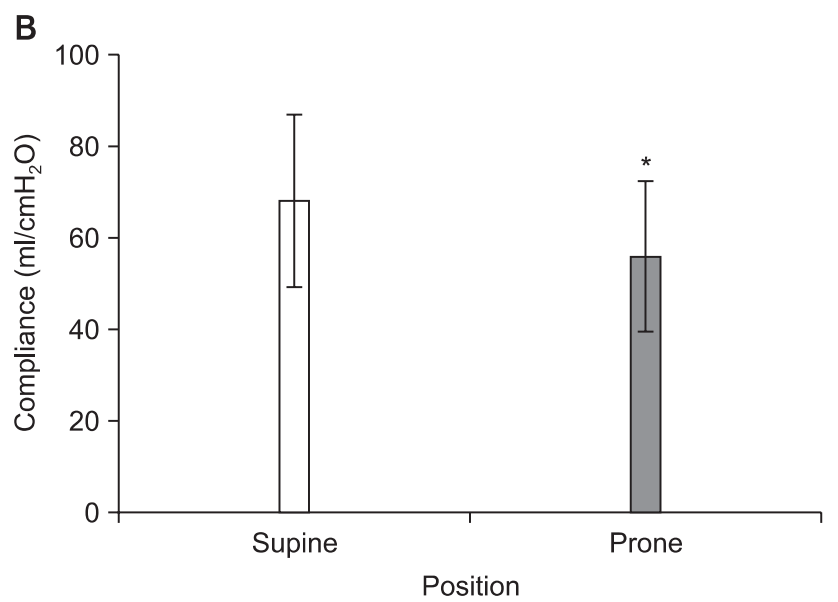

Fig. 2. Change in airway resistance (A) and dynamic compliance (B) when moving from the supine to prone position. $* \mathrm{P}<0.05$ versus the supine position. 
$\mathrm{P}_{\text {plat }}(10.8 \pm 2.3 \mathrm{mmHg}$ vs. $11 \pm 2.5 \mathrm{mmHg}, \mathrm{P}>0.05)$. In addition, the difference between the PIP and $\mathrm{P}_{\text {plat }}$ increased significantly (4.6 $\pm 0.9 \mathrm{mmHg}$ vs. $5.7 \pm 1.7 \mathrm{mmHg}, \mathrm{P}<0.05$, Fig. 1 ).

$\mathrm{R}_{\mathrm{aw}}$ increased significantly when the body positioning was changed in a similar manner as the difference between the PIP and $\mathrm{P}_{\text {plat }}$ increased significantly $\left(22.7 \pm 9.8 \mathrm{cmH}_{2} \mathrm{O} / \mathrm{ml} / \mathrm{s}\right.$ vs. $\left.25.3 \pm 11.6 \mathrm{cmH}_{2} \mathrm{O} / \mathrm{ml} / \mathrm{s}, \mathrm{P}<0.05\right)$. However, $\mathrm{C}_{\text {dyn }}$ significantly decreased $\left(68.2 \pm 18.8 \mathrm{ml} / \mathrm{cmH}_{2} \mathrm{O}\right.$ vs. $56.2 \pm 16.5 \mathrm{ml} / \mathrm{cmH}_{2} \mathrm{O}, \mathrm{P}<$ 0.05, Fig. 2).

\section{Discussion}

These results revealed an increase in PIP but not in the $\mathrm{P}_{\text {plat }}$. The $\mathrm{P}_{\text {plat }}$ was measured at the state when the gas flow was blocked. The difference between the PIP and $\mathrm{P}_{\text {plat }}$ is the pressure needed to overcome $\mathrm{R}_{\mathrm{aw}}$. Therefore a constant $\mathrm{P}_{\text {plat }}$ with an increase in PIP indicates an increase in $\mathrm{R}_{\mathrm{aw}}$ [9]. These results revealed a decrease in $\mathrm{C}_{\mathrm{dyn}}$. $\mathrm{C}_{\mathrm{dyn}}$ is affected by the inspiratory gas flow, $\mathrm{R}_{\mathrm{aw}}$ and the equilibrium between the proximal tip and distal end of the airway [10]. A decrease in $\mathrm{C}_{\mathrm{dyn}}$ occurs in cases of an increase in $\mathrm{R}_{\mathrm{aw}}$ or a decrease in pulmonary and thoracic elasticity [11]. Therefore, the increase in PIP was attributed to the increase in $\mathrm{R}_{\mathrm{aw}}$ or decrease in $\mathrm{C}_{\mathrm{dyn}}$.

According to previous studies on the prone position, abdominal movement is limited when the abdomen is pressed and the internal organs push the diaphragm in the direction of the head [2-4]. Moreover, the weight of the trunk reduces the diameter of the chest wall and limits movement, which reduces the respiratory compliance by $20-30 \%$. Therefore, the increase in PIP is believed to be due to a decrease in pulmonary compliance. In contrast, if the patient is positioned where the upper chest and pelvis are supported allowing for the free movement of the abdomen, as Smith [8] suggested, it would produce less restriction of the chest wall than other body positioning apparatuses. Moreover, Cho et al. [12] stated that there are no significant changes in respiratory or pulmonary compliance as the patient's position was changed from the supine to the prone position. This is because compared to other body positioning apparatuses, the Jackson table does not press the upper abdomen but allows free movement of the abdomen, and has the least effect on the respiratory system. In this study, the patients were moved to the prone position using a Jackson table, so the cause for the increase in PIP does not appear to be due to the effects of a decrease in pulmonary compliance but from an increase in $\mathrm{R}_{\mathrm{aw}}$.

A variety of reasons can lead to an increase in $\mathrm{R}_{\mathrm{aw}}$. The increase in $R_{a w}$ may be due to a problem with the endotracheal tube, such as kinking of the tube or overexpansion of the air-cuff, or it may be due to an obstruction of the airway by secretions, blood and other objects [13]. The increase in $\mathrm{R}_{\mathrm{aw}}$ after placing the patient in the prone position was attributed primarily to airway secretion. In such cases, the cause for the increase in $\mathrm{R}_{\mathrm{aw}}$ is likely to be an endotracheal tube obstruction, airway obstruction due to mucus, or bronchospasm, which can be improved if the secretion is removed. There are reported cases where patients in the prone position repeatedly had obstructed endotracheal tubes due to a secretion in the lung or blood drainage due to the force of gravity [14-16]. Baydur et al. [17] also stated that the increase in respiratory and pulmonary resistance occurs from the accumulation of airway secretion with time. This study is limited in that it made observations after only a short period of 10 minutes after the changing the body position. To confirm the cause, measurements of the $\mathrm{R}_{\mathrm{aw}}$ should be carried out after a longer time has passed since taking up the prone position.

The other cause can be considered to be a decrease in the chest wall elasticity. Pelosi et al. [5] stated that moving the patient into the prone position compared to the supine position increases the respiratory resistance by $20 \%$. This $20 \%$ increase in respiratory resistance is believed to be due to a decrease in thoracic elasticity because the tidal volume is maintained at a constant rate. In addition, Cho et al. [12] explained that the increase in chest wall compliance occurs when the apparatus used to support the upper chest in the body positioning changes presses the upper chest, which can explain the increase in $R_{a w}$.

Considering the increase in $\mathrm{R}_{\mathrm{aw}}$ due to kinking of the endotracheal tube, most procedures with the patient in the prone position use a wire-reinforced tube to minimize kinking. Kil and Bishop [18] reported that kinking of the endotracheal tube leads to turbulent flow, which increases the airway pressure and resistance. The wall of a wire-reinforced tube is rough compared to a polyvinyl chloride tube and creates friction with air particles, which causes turbulent flow and increases the resistance. In the prone position, a wire-reinforced tube is used to prevent kinking of the endotracheal tube but the neutral position of the head causes the endotracheal tube to curve instead of straighten. This also may cause an increase in $\mathrm{R}_{\mathrm{aw}}$.

The total respiratory resistance is proportional to PIP - $\mathrm{P}_{\text {plat }}$ and inversely proportional to the inspiratory flow rate [19]. In this study, the inspiratory flow rate was kept at a constant rate. Hence, an increase in $\mathrm{R}_{\mathrm{aw}}$ increased the difference between the PIP and $\mathrm{P}_{\text {plat }}$. In addition, $\mathrm{C}_{\mathrm{dyn}}$ can be found by dividing the tidal volume by PIP. Thus, the increase in $\mathrm{C}_{\mathrm{dyn}}$ can be explained as an increase in $\mathrm{R}_{\mathrm{aw}}$.

Backofen and Schauble [20] and Yokoyama et al. [21] reported that changing the patient to the prone position decreases the cardiac index $(24.4 \%$ and $17.2 \%)$ and increases the total systemic vascular resistance. The decrease in cardiac index is due to a decrease in venous circulation from venostasis in the leg and an increase in thoracic pressure. However, the change 
in blood pressure is not commonly the result of an increase in total systemic vascular resistance due to activation of the sympathetic nervous system following a decrease in cardiac output [22]. These results also showed no significant changes in blood pressure or heart rate in either the supine or prone position.

The prone position for patients with acute respiratory failure is well-known for improving hypoxia and aiding in the correction of V/Q mismatching [23]. On the other hand, only a few studies have examined the changes in oxygenation and V/Q matching under general anesthesia. Lumb and Nunn [24] reported that the prone position for normal, conscious patients increases their functional residual capacity. Pelosi et al. [5] stated that changing to the prone position under general anesthesia increases the functional residual capacity and $\mathrm{PaO}_{2}$. Previously, pulmonary blood flow was more in the dependent area than in the independent area [25]. However, magnetic resonance imaging measurements in recent animal studies showed that the pulmonary blood flow moves towards an independent area of the back regardless of the change to the prone position $[26,27]$. This was explained as being due to the structurally low pulmonary vascular resistance of the lung's side towards the back rather than the effects of gravity on pulmonary blood flow. In the prone position, the structural characteristics of the airway and pulmonary vein, rather than the effects of ventilation or gravity, allows for better ventilation in the back area. When changing from the supine to prone position, such an increase in lung volume and improvement in the V/Q matching are known to improve oxygenation [4]. In the present study, $\mathrm{PaO}_{2}$ and $\mathrm{PaCO}_{2}$ differed from the mean values but the changes were not significant. The values were taken 10 minutes after changing to the prone position but these values should have been taken after a longer time had passed.

In conclusion, when changing the patient from the supine to prone position, the PIP can increase even when pressure on the abdomen is minimized using a Jackson surgical table. This is not only because of the decrease in pulmonary and chest wall compliance but also from the effects of the increase in $\mathrm{R}_{\mathrm{aw}}$. Therefore, the increase in PIP on patient monitoring should not be attributed only to a decrease in compliance caused by the prone position, but also to an increase in $\mathrm{R}_{\mathrm{aw}}$ caused by the drainage of secretive fluids due to gravity from the change in body position, as well as to the location and kinking of the endotracheal tube.

\section{References}

1. Kim BS. Anesthesia and pain management. 2nd ed. Seoul, Elservier Korea. 2009, pp 929-73.

2. Warner MA. Patient positioning. In: Clinical Anesthesia. 5th ed. Edited by Barash PG, Cullen BF, Stoelting RK: Philadelphia, Lippincott-Raven Publishers. 2006, pp 657-61.

3. Lynch S, Brand L, Levy A. Changes in lung thorax compliance during orthopedic surgery. Anesthesiology 1959; 20: 278-82.

4. Manna EM, Ibraheim OA, Samarkandi AH, Alotaibi WM, Elwatidy $\mathrm{SM}$. The effect of prone position on respiratory mechanics during spinal surgery. Middle East J Anesthesiol 2005; 18: 623-30.

5. Pelosi P, Croci M, Calappi E, Cerisara M, Mulazzi D, Vicardi P, et al. The prone positioning during general anesthesia minimally affects respiratory mechanics while improving functional residual capacity and increasing oxygen tension. Anesth Analg 1995; 80: 955-60.

6. Palmon SC, Kirsch JR, Depper JA, Toung TJ. The effect of the prone position on pulmonary mechanics is frame-dependent. Anesth Analg 1998; 87: 1175-80.

7. Dohi S, Gold MI. Pulmonary mechanics during general anaesthesia. The influence of mechanical irritation on the airway. Br J Anaesth 1979; 51: 205-14.

8. Smith RH. One solution to the problem of the prone position for surgical procedures. Anesth Analg 1974; 53: 221-4.

9. Bigatello LM, Davignon KR, Stelfox HT. Respiratory mechanics and ventilator waveforms in the patient with acute lung injury. Respir Care 2005; 50: 235-45.

10. Lu Q, Vieira SR, Richecoeur J, Puybasset L, Kalfon P, Coriat P, et al. A simple automated method for measuring pressure-volume curves during mechanical ventilation. Am J Respir Crit Care Med 1999; 159: 275-82.

11. Kárason S, Søndergaard S, Lundin S, Wiklund J, Stenqvist O. A new method for non-invasive, manoeuvre-free determination of "static" pressure-volume curves during dynamic/therapeutic mechanical ventilation. Acta Anaesthesiol Scand 2000; 44: 578-85.

12. Cho SY, Noh GJ, Yeom JH, Shin WJ, Kim YC, Kim KH, et al. The effect of prone position on pulmonary compliances by anesthesia duration. Korean J Anesthesiol 2000; 38: 997-1001.

13. Szekely SM, Webb RK, Williamson JA, Russell WJ. The Australian Incident Monitoring Study. Problems related to the endotracheal tube: an analysis of 2000 incident reports. Anaesth Intensive Care 1993; 21 : 611-6.

14. Grimmett WG, Poh J. Clearance of an obstructed endotracheal tube with an arterial embolectomy catheter with the patient in the prone position. Anaesth Intensive Care 1998; 26: 579-81.

15. Lin JA, Wong CS, Cherng CH. Unexpected blood clot-induced acute airway obstruction in a patient with inactive pulmonary tuberculosis during lumbar spine surgery in the prone position: a case report. Acta Anaesthesiol Taiwan 2005; 43: 93-7.

16. Son JS, Kim JH, Lim HS, Ko SH. Acute obstruction of an endotracheal tube due to large mucous plug: removed using flexible fiberoptic bronchoscopy: a case report. Korean J Anesthesiol 2005; 49: 694-7.

17. Baydur A, Sassoon CS, Stiles CM. Partitioning of respiratory mechanics in young adults: effects of duration of anesthesia. Am Rev Respir Dis 1987; 135: 165-72.

18. Kil HK, Bishop MJ. Head position and oral vs nasal route as factors determining endotracheal tube resistance. Chest 1994; 105: 1794-7.

19. Tobin MJ. Principles and practice of mechanical ventilation. 2nd ed. New York, McgRaw-Hill. 2006, pp 976-84.

20. Backofen JE, Schauble JF. Hemodynamic changes with prone 
position during general anesthesia. Anesth Analg 1985; 64: 194.

21. Yokoyama M, Ueda W, Hirakawa M, Yamamoto H. Hemodynamic effect of the prone position during anesthesia. Acta Anaesthesiol Scand 1991; 35: 741-4.

22. Wadsworth R, Anderton JM, Vohra A. The effect of four different surgical prone positions on cardiovascular parameters in healthy volunteers. Anaesthesia 1996; 51: 819-22.

23. Pelosi P, Brazzi L, Gattinoni L. Prone position in acute respiratory distress syndrome. Eur Respir J 2002; 20: 1017-28.

24. Lumb AB, Nunn JF. Respiratory function and ribcage contribution to ventilation in body positions commonly used during anesthesia.
Anesth Analg 1991; 73: 422-6.

25. Kaneko K, Milic-Emili J, Dolovich MB, Dawson A, Bates DV. Regional distribution of ventilation and perfusion as a function of body position. J Appl Physiol 1966; 21: 767-77.

26. Glenny RW, Lamm WJ, Albert RK, Robertson HT. Gravity is a minor determinant of pulmonary blood flow distribution. J Appl Physiol 1991; 71: 620-9.

27. Prisk GK, Yamada K, Henderson AC, Arai TJ, Levin DL, Buxton RB, et al. Pulmonary perfusion in the prone and supine postures in the normal human lung. J Appl Physiol 2007; 103: 883-94. 